\title{
El legado testamentario de Lope de Barrientos
}

\author{
Paloma Cuenca Muñoz \\ Universidad Complutense
}

\section{EDICIÓN PALEOGRÁFICA?}

Si nos atenemos al contenido de las disposiciones testamentarias que fray Lope de Barrientos manda redactar al notario Velasco Sánchez, para que sirvan como su última voluntad, hay que señalar la posible exigencia de cuatro copias de dicho documento que poseen idéntico valor legal ${ }^{2}$. Para realizar la presente edición hemos tenido acceso a la copia que se encuentra custodiada por las monjas dominicas de clausura, en Medina del Campo, quienes amablemente nos prestaron el manuscrito el tiempo suficiente como para poder lograr una reproducción del mismo ${ }^{3}$. A partir de aquí, podemos ofrecer una edición paleográfica del testamento de uno de los personajes históricos más importantes durante los reinados de Juan II de Castilla y de su hijo, Enrique IV ${ }^{4}$.

Por lo que se refiere al conjunto del testamento, resulta muy difícil poder establecer unas líneas básicas que, a modo de regesto, den cuenta

1 En este articulo tan sólo vamos a abordar la transcripción paleográfica del testamento. Por motivos de extensión, aparecerá una segunda parte donde se analizará dicho texto desde el punto de vista que proponen tanto la paleografía como la diplomática. Quisiera expresar mi agradecimiento a las profesoras Pilar Saquero, por su ayuda con los pasajes en latin, y M. ${ }^{2}$ Luisa Palacio, por sus continuos consejos.

2 Las citas del testamento se corresponden con la foliación original que aparece en el texto que aquí se edita. Vid. fols. $15 \mathrm{r}-\mathrm{v}$.

3 Quiero expresar aqui mi agradecimiento a Antonio Sánchez del Barrio que fue nuestro guía y mentor en Medina del Campo, y a quien se deben las diligentes gestiones que nos permitieron acceder al documento que se edita.

4 Sobre la figura de Lope de Barrientos véase entre otros trabajos: Luis G.A. GeTiNo, Vida y obra de fray Lope de Barrientos. Salamanca. Anales Salmantinos, 1927; Lope de Barrientos, Refundición de la crónica del halconero, ed. Juan de Mata Carriazo, Madrid, Espasa-Calpe, Colección de Crónicas Españolas, IX, 1946; Paloma Cuenca Muñoz, El “Tractado de la divinança de Lope de Barrientos, Cuenca, Instituto Juan de Valdés, 1994. 
de su contenido, ya que dentro de una forma eminentemente reiterativa apenas existen frases cuya información parezca redundante.

A pesar de ello, y a riesgo de no mencionar aspectos importantes, el testamento se puede dividir en tres partes principales. En un primer momento Barrientos se ocupa de la parte legal, y aqui no valida el testamento en sí mismo, sino su posibilidad de testar lo que él considera como bienes propios (fols. $1 r-7 \mathrm{~V}$ ). Inmediatamente después comienzan las mandas (fols. $8 r-13 v$ ), donde podemos verificar que la renta de fray Lope fue en aumento a lo largo de su vida pontificia, ya que es llamativo no sólo la cantidad de sirvientes que posee y su variada tipología, sino la cuantía de los bienes que deja a cada uno de ellos. Dentro de este apartado también aparecen, como es lógico, sus familiares, en este caso representados por dos sobrinos, Pedro y Diego de Barrientos ${ }^{5}$. Una parte importante de su herencia queda reservada para monasterios e iglesias de casi toda España; pero el mayor heredero de los cuantiosos bienes del obispo no es otro que el Hospital de Santa María de la Piedad en Medina del Campo, que conforma su principal fundación, consciente de lo costoso que era mantener un edificio de esas características.

Por último (fols. 14r-16r) aparece el nombramiento de albaceas y testigos. La validación del testamento se concluye con el signo y la apostilla notarial de veracidad documental.

\section{Criterios de edición}

A pesar de que la transcripción paleográfica de cualquier texto debe realizarse según determinados criterios generales, es quizás conveniente señalar de manera explícita, tanto algunos de los usos más habituales, como otros que se pueden considerar inherentes a las particularidades que presenta cada texto en concreto. Así:

- Se mantienen las grafías $\mathrm{u} / \mathrm{v}$, con independencia del valor fonético que tengan; pero se igualan las grafías $j / i$ en lo que atañe a su valor vocálico.

5 A pesar de que Barrientos otorga a los dos el mismo grado parental, algunos detalles del texto hacen pensar que hubiera diferencia entre ellos, como por ejemplo, el hecho de que cuando nombra a Pedro de Barrientos omita el nombre de su progenitor, y lo mencione siempre en el caso de Diego. Asimismo la función destinada a Diego es la de ser albacea testamentario, frente a la de Pedro que es la de un familiar más directo, acompañar el cuerpo durante todas las exequias. 
- Se mantiene la doble nasalidad, pero sin resolver aún en $\tilde{n}$.

- Se respeta el uso de las consonantes dobles ( $-\mathrm{ss}, \mathrm{ff}-\ldots$ ).

- La $R$ - se resuelve en $r r-o R$ - según el caso lo requiera.

- Se desarrollan las abreviaturas sin señalizar.

- Se utilizan los corchetes cuadrados [ ] para lo que se añada al texto por parte del editor. Por el contrario, los ángulos < > se usan para suprimir del texto alguna repetición innecesaria.

- Las expresiones breves en latín se señalan con letra cursiva, y se usan las comillas para los textos de mayor extensión citados en latín.

- Se señala entre paréntesis el comienzo de cada uno de los folios que conforman el original, con su numeración correspondiente.

- La puntuación, el criterio de mayúsculas y la acentuación se realiza según el modo actual.

- El cuerpo de notas lo conforman tanto las notas aclaratorias propias del editor, como la transcripción de los ladillos que aparecen en el texto, siempre debidamente indicado.

- La forma equivalente a la conjunción copulativa y se resuelve en et para el texto en latín y en $e$ para el romance.

- Se acentúa nós en su función pronominal.

Testamento del sennor obispo don fray Lope de Barrientos, en 17 días del mes de noviembre, año de 1454. Ante Velasco Sánchez, notario apostólico.

(Fol. 1r) In nomine Sancte et Individue Trinitate, Patris, et Fillii, et Spiritus Sancti. Por quanto la muerte es cosa natural e el término de la presente vida muy dubdoso, por lo qual todo omne deve estar aparejado ordenando su ánima, e fazienda, e bienes que Dios le dio a su seruiçio, e pro de su ánima para quando nuestro Señor le llamare para sý. Por ende, nós don Lope de Barrientos, obispo de Cuenca, chanciller mayor del Rey nuestro sennor, e su confesor, e oydor de la su audiencia e del su consejo, por espeçial poder, licencia a dispenssaçión que para esto tenemos de nuestro muy sancto padre Eugenio Quarto de sancta memoria, su thenor de la qual de verbo ad verbum es este que se sigue:

"Eugenius, episcopus seruus seruorum dei, venerabili fratri Luppo episcopo Conchense salutem et appostolicam benedictionem. Devocionis tue 
probata sinceritas, quam ad nos et sedem appostolicam contrahere dinoscetis promeretur vt personam tuam sinceris afectibus prosequentibus peticionibus tuis, quamtum cum Deo posumus faborabiliter annuamus. Hic est quod nos tuis qui vt aseris ordinis fratrum predicatorum profesor existis, in hac parte suplicationibus inclinati fraternitati tue vt quod forsam iam tibi regia vel alia quavis largicione donata et conccesa fuerunt, seu quoad te allias vndecumque et quomodocumque non tamen (fol. $1 \mathrm{v}$ ) a Conchense cui preesses dinosceris vel alliis ecclesis quibus prefuisti allias tamen liccite ecclesiam, si intuitu dignitatis peruenerint rettinere et alia quecumque quotumcunque et qualiacunque possessiones, terras, castra, villas, loca, vasalos, rura, peccunias, iocalia, ceteraque, mobilia et inmobilia bonaque tibi donabuntur vel concedentur autem alia non tamen Conchensibus seu alliis catedralibus vel metropolitanis ecclesiis, quibus te forsam in posterum preesse contigerint ad te ecclesie intuitu huismodi perueni et forsitam in futurum adquirere et retinere ac prima omnia et singula consanguineis amicis ac servitoribus tuis et quibuscumque alliis personis, nec non inpios usus vel qualitercumque et quomodocumque donatione inter vivos seu in morte aut aliud pro tue voluntatis libito donare, relinquere, legare, testari et de illis disponere ac ordinare libere et liccite valeas quodque donacio testamentum, disposicio et ordinacio huiusmodi valleant plenamque roboris firmitatem obtineant ac illorum executiones seu fidecomisarii per te pro tempore deputati, ad ipsorum plenariam execucionem proccedere posint et debeant, auctoritate appostolica tenore presencium conccedimus pariter et indulgemus non obstante profesione per te facta ac iuribus, nec non constitucionibus et ordinacionibus appostolice ac ordinis et ecclesiarum predictarum iuramento confirmacione appostolica, vel quavis firmiter alia roborate statutis et consuetudinibus ceterisque contrariis quibuscumque. Nulli ergo omino hominum liceat hanc paginam nostre conccesionis infringere vel ei ausu temerario contraire. Si quis autem hoc ateptare presupuserit indignationem dei omnipotente et beatorum Petri et Pauli apostolorum eius se nouerit incursurum. Datum Rome, apud sanctum Petrum anno incarnacionis Dominice (fol. $2 r$ ) millesimo quadricentesimo quadragesimo sexto, quarto idus nouembris, pontificatus nostri anno sexto deccimo".

Por ende, asý por virtud de este poder, liçencia e dispensaçión como por la facultad que en esta parte tenemos e nos da el derecho, e puesto que la dicha facultad non touieramos, nós podieramos e podemos ordenar, e disponer, e mandar todo lo infra scripto por intuitu ${ }^{6}$ de nuestra persona, por los muchos e leales seruiçios que fezimos a los muy esclaresçidos

- «En atención, en consideración a, por razón de". 
rreyes don Juan e don Enrrique su fijo, rreyes de Castilla ${ }^{7}$ e de León, de los quales rrescebimos e ouimos muchas merçedes, asý en bienes rraýzes commo en bienes muebles, e maravedis de juro e de heredad, e raçión e quitaçión, e de por vida en tanto número que pudieran bastar a conplir todas las mandas yuso contenidas. Para lo qual, demás de la facultad que tenemos de nuestro Sancto Padre para testar de las rrentas e frutos que rresçebimos de las yglesias e obispados donde avemos seýdo perlado, tenemos otra espeçial facultad de nuestro muy Sancto Padre Nicholao para donar e distribuyr todo lo que asý ovimos, ganamos e adquirimos, asý por intuitu de nuestra persona e seruiçios que fezimos a los dichos sennores Reyes, commo por intuito de las dignidades que avemos avido, segund que en la dicha liçencia e poder se contiene, su thenor de la qual es este que se sigue:

«Nicholaus, episcopus seruus seruorum Dei Venerabili fratri Luppo episcopo Conchense, salutem et appostolicam benedicionem. Exigit sincere deuocionis integritas qua nos per Romanam revereris ecclesiam, vt peticiones tuas ad exaudicionis gratiam (fol. $2 v$ ) quam cum Deo posumus faborabiliter admitamus sane per parte tua nobis nuper exibita peticio continebat quod olim felicis recordacionis Eugenius papa Quartus, predeccesor noster, tibi tunc episcopo Abulense de omnibus et singulis ad te pertinentibus pro tempore mobilibus et inmobilibus bonis vndecumque prima ecclesiam, si raccione Abulensie cui tunc preeras ac cuiuscumque alterius ad quam forsam te transferri contigerit, ecclesiarum ad te quomodolibet catenis preuenisent vel in posterum peruenirent, vsque ad sumam sex millium florenorum auri de camera testandi seu disponendi plenam et liberam per suas litteras licenciam elargitus fuit, prout in eisdem litteris dicitur plenius contineri cum autem sicut eadem peticio subiungebat tibi preserti posquam de perssona tua dicte ecclesie Abulensi prouisum fuit, et deinde ad ecclesiam Conchensem cui preesse dinosceris translatus stetistis quam plura mobilia et inmobilia bona per nonnullos reges, principes et allias inferiores personas donata seu alliis conccesa extiterint vel ad te peruenerint ac forsam conccedentur seu peruenient in futurum, et pro eo quod ordinis fratrum predicatorum profesor existis a nonnullis revocetur in dubium, an sic donata et que ad te peruenerunt seu donabuntur et peruenient in posterum adquirere, ac de illis pro tue voluntate libito disponere et ordinare libere ac liccite possis, et si de illis disponeres et ordinares an prima in literis conccesionis predicte conprehendantur et conprehendi debeant, nos

7. Mg. en humanistica: don Juan y don Enrique, su hijo. 
tuis in hac parte suplicacionibus inclinati fraternitati tue, quod (fol. $3 r$ ) omnia et singula que tibi actenus donata fuerunt vel donabuntur aut iam ad te peruenerunt seu peruenient in posterum ex regum principum vel aliarum inferiorum personarum, largicione seu alia qualitercumque intuito vel respectu persone tue quecumque, quotcumque et qualiacumque et cuiusuis valoris sint acquirere et retinere, nec non de illis tam in vita quam in morte pro tue voluntatis libito donare ac de illis, nec non ipsius liccencie vigore vsque ad sumam sex millium florenorum predictam de bonis que ad te ex frutibus, reditibus et prouenientibus quibus actenus prefuisti et ad quas te in posterum transferri contigerit ecclesiarum seu alia racione ecclesiarum huiusmodi peruenerunt seu peruenient in futurum, dummodo non sint altaris vel altarium seu alicui eclesiastice vsui deputata testari disponere et ordinare libere ac liccite valeas, quod dicti ordinis profesor sis vt prefertur ac constitucionibus et ordinacionibus appostollice nec non prefacti ordis iuramento confirmacione appostolica vel quauis firmitate alia roboratis statutis et consuetudinibus ceterisque contrariis, nequaquam obstante auctoritate appostolica tenore presencium concedimus pariter et indulgemus. Voluimus autem quod ex bonis supradictis, equalem porcionem ecclesie vel ad allios pios vsus dimittas. Nulli ergo omnino hominum licceat hanc paginam nostre conccesionis et voluntatis infringere vel ei ausu temerario contraire. Si quis autem hoc ateptare presupserit indignationem omnipotentis Dei et beatorum Petri et Pauli apostolorum eius se nouerit incursurum. Datum Rome, apud sanctum Petrum anno incarnacionis Dominice millesio quadracentesimo quadragesimo septimo cuarto, decimo calendas maii, pontificatus nostri anno primo".

Por ende, ordenamos e estableçemos nuestro testamento e postrimera voluntad a seruicio de Dios e de la virgen sancta María nuestra sennora, e a pro e saluaçión de nuestra ánima, en la manera syguiente: Primeramente mandamos nuestra ánima a nuestro sennor Dios que la crió e redimió por su preçiosa (fol. $3 v$ ) sangre, suplicando humilmente que vsando de su infinita clemencia, pues la nuestra ánima miserable llena de pecados non es digna nin meresçedora de la gloria infinita, quiera dexar el rrigor de la justiçia por la qual ella es obligada a infinitas penas, e vsar con ella de la su inmensa misericordia, dándole parte en los méritos de la su pasión sagrada e leuarla a la su gloria, por rreuerencia de la qual dicha pasyón de nuestro rredenptor Ihesuchristo porque Él aya piedad de nuestra ánima e la quiera perdonar para la leuar a la su santa gloria.

Nós por la presente rremitimos todas e qualesquier injurias que qualesquier persona o personas nos ayan fecho en cualquier manera, e ansý rrogamos e pedimos dé gracia a todas e qualesquier otras personas que 
nós ayamos enjuriado, o otro o otros por nćs, que por la dicha pasyón de nuestro Sennor Ihesuchristo nos quieran perdonar, que Dios nuestro Sennor les perdone sus pecados ${ }^{8}$. Iten mandamos nuestro cuerpo miserable a la tierra de que fue formado; que lo entierren e sepulten en la nuestra capilla mayor del nuestro ospital de la villa de Medina del Campo, en el logar que para ello tenemos deputado, e lo pongan debaxo del vulto de alabastro segund e por la vía que lo nós tenemos fecho e ordenado, en medio de la dicha nuestra capilla del dicho nuestro ospital. Iten mandamos que el día que nós fallesçieremos desta presente vida den a todos nuestros criados, capellanes, escuderos, e pajes, e omnes de pie, e moços de espuelas, e ofiçiales que agora de continuo nos siruen, de vestir de panno negro de blanquita ten[n]ido, e que trayan este dicho vistuario por espaçio de vn anno, e que en fin del dicho anno mandamos a nuestros albaçeas e testamentarios que den a cada vno de aquellos que lo ovieren traýdo, para su vistuario de los clérigos e cape (fol. 4r) llanes e escuderos dos mill maravedís a cada vno, e a cada paje mill maravedís, e a cada omne de pie seyçientos maravedís, e a los moços de espuelas a cada vno quinientos maravedís, los quales dichos maravedís mandamos que sean dados a los dichos nuestros criados con condición que vayan con nuestro cuerpo e lo aconpannen fasta que sea sepultado en la capilla del dicho nuestro ospital, e estén ende fasta ser conplidas nuestra obsequias; e después de complido el anno e acabadas las honrras del cabo del anno, les sean dados los dichos maravedís para su vistuario e quitar luto segund dicho es. Pero mandamos que durante el tiempo de las dichas obsequias a todos los dichos nuestros criados que asý aconpannaren al dicho nuestro cuerpo e fueren presentes a las dichas nuestras obsequias, que les den e paguen sus rraçiones continuas para el mantenimiento de los días que allý estuuieren en las dichas obsequias; pero sy algunos de los dichos nuestros criados fueren absentes, por tal manera que non pudiesen acompannar el dicho nuestro cuerpo, mandamos que sy vinieren a las dichas obsequias les sea dado el panno que les mandamos dar para el luto, e les sean pagadas sus rraçiones de mantenimiento por los días que allí estuuieren en las dichas obsequias. E demás desto, mandamos que sean pagados a los dichos nuestros criados las rraçiones de tres meses después de las dichas obsequias, a cada vno, demás de lo que nós les mandamos en este nuestro testamento.

- A partir de aquí, delante de la palabra Item, asi como en otros momentos puntuales, aparece el signo de párrafo; en esta edición se omite dicho signo con la única intención de conseguir una mayor fluidez en el proceso de lectura. 
Iten mandamos que commo nuestra ánima saliere de la carne digan luego sobre el cuerpo vna misa de rrequiem, e se canten vnas obsequias priuadas, e luego syn dillacçión alguna, sea nuestro cuerpo leuado a la dicha nuestra capilla del dicho nuestro ospital, e sea luego ende sepultado, donde mandamos que se fagan otras obsequias por nuestra ánima en esta guisa: Primeramente, que commo llegare el cuerpo le pongan en el dicho nuestro vulto secretamente, dexando el rresçibimiento del dicho cuerpo a dispusiçión de nuestros (fol. $4 v$ ) albaçeas que fagan saber al cabildo de los clérigos de la hermandad de Medina, Aréualo, Olmedo e Alua, e a los cabildos de los cofrades del nuestro ospital e de Sant Andrés, e Sancta María del Castillo, e de la Trinidad e a los otros todos cabildos de la dicha villa de Medina do nós somos cofrade, que luego para el primero domingo syguiente, después de llegado el dicho cuerpo, sean llamados los cabildos de los clérigos de la dicha villa de Medina e todos los rreligiosos de los monesterios de Sancto Domingo, e de Sant Françisco, e de las otras órdenes de la dicha villa de Medina, e los frayres de los monesterios de Ávila, e de Segouia, e de Aréualo, e Olmedo, e Sancta María de Nieua, e de Sant Pablo de Valladolid, e de Sant ${ }^{9}$ Illefonso de Toro, e de Sancto Tomás de Oterdesyllas que vengan de cada vno destos dichos monesterios de Ávila e Segouia, Aréula e Olmedo, Nieua e Valladolid, Toro e Oterdesillas seys frayres. E todos asý ayuntados, los que venir quysieren para el dicho primero domingo después de llegado el dicho nuestro cuerpo, celebren las obsequias e honrras el dicho domingo a las viesperas, e otro día lunes a la misa faziendo vna cama con sus andas cubiertas de seda negra en medio de la dicha yglesia del dicho nuestro ospital donde se fagan los dichos ofiçios, para los quales dichos ofiçios mandamos que se pongan çiento e veynte çirios de çera, de peso de quatro libras cada vno, por rrespecto de las oras que nuestro Sennor estuuo en el sepulcro por cada ora tres çirios, porque ansý commo Él después de las dichas oras rresurgió del sepulcro, asý plega a la su clemençia que la nuestra ánima rresurga con los sus sanctos en la su sancta Iglesia. E asymesmo, se fagan veynte ( $f \circ$ l. $5 r$ ) e quatro fachas de peso cada vna de seys libras, e los platos de candelas de rrepulgo ${ }^{10}$, en que ayan las candelas que abasten para las dichas obsequias e misas, e mandamos que este día se faga ofertorio de pan e vino e carne, lo qual se lieue en treynta azémilas; las diez azémilas que lieuen diez cargas de trigo, e las otras diez, diez

9 Mg. en humanística: Alfonso.

10 "La torcedura que se hace al lienzo, paño o seda, cosida con hilo o seda a pespunte o venilla". Se refiere a platos que posean un tipo de adorno similar a éste. 
cargas de vino, e las otras diez, veynte carneros; por tal manera que se fảga todo tan conplidamente como en tal caso se rrequiere. E mandamos que den a los clérigos, e cabildo, e cofradias de los dichos cabildos de Medina todo lo acostunbrado, e allende desto, porque más cargo tengan de rrogar a Dios por nuestra ánima e de nuestros defuntos, que les den otro tanto de más de lo acostunbrado. $\mathrm{E}$ a los monesterios de la dicha villa de Medina, a cada vno quinientos maravedís; e a los monesterios susodichos que son de fuera de Medina, e enbiaren los dichos seys frayres, a cada vno mill maravedís, pero sy menos enbiaren, que los paguen aqueste respecto pero que sean tenudos todos juntos de estar a los dichos ofiçios, e obsequias, e honrras el dicho domingo a las biesperas e el dicho lunes a la missa. Iten mandamos que los monesterios de Sancta María la Real e de Sancta Clara, por ser duennas ençerradas e non pueden venir a las dichas obsequias, que las canten ellas en los dichos sus monesterios, e den a cada vn monesterio quinientos maravedís por seruicio de Dios e por su trabajo.

Iten mandamos que depués de fechas estas dichas obsequias e por la manera susodicha, que luego este dicho lunes en la tarde e otro día martes syguiente todos los dichos clérigos e frayres de la (fol. $5 \mathrm{v}$ ) dicha villa, e los frayres de fuera de los ctros logares susodichos, digan otras semejantes obsequias en el dicho monesterio de Sant Andrés de la dicha villa de Medina, por nuestra ánima e de nuestros padre e madre, e que vengan ende asymesmo los dichos cabildos e cofradías de la dicha villa, e que se lieue otra tanta ofrenda de pan, e vino, e carne, commo mandamos leuar al dicho nuestro ospital a las dichas nuestras primeras obsequias, e toda la çera que ardiere en las dichas primeras obsequias en el dicho nuestro ospital que la lieuen e pongan en el dicho monesterio de Sant Andrés para que arda en las dichas segundas obsequias; e después mandamos que toda la çera que sobrare sea para el dicho monesterio de Sant Andrés.

Iten mandamos que el dicho lunes de nuestra sepultura fasta nueue días primeros syguientes, se digan cada día treynta misas por nuestra ánima de rrequiem rezadas, e sean llamados para las dezir treynta prestes clérigos e religiosos de los más honestos que se fallaren en la comarca, a los quales asymesmo mandamos que todos juntamente cada día de los dichos nueue días a las viespras, dentro en la dicha nuestra capilla, digan vna vigilia de tres liçiones, e acabada la dicha vigilia todos juntamente vengan a dezir sobre nuestra sepultura vn rresponso cantado; e mandamos a nuestros albaçeas que den a cada vno de los dichos clérigos e rreligiosos que vinieren de fuera treynta maravedís a cada vno cada día, e a los que fueren de la dicha villa de Medina a cada vno cada día veynte maravedís; e mandamos que todos los dichos clérigos e rreligiosos, (fol. 
$6 r$ ) acabadas las dichas treynta misas cada día de dezir los dichos nueve dias, digan todos juntamente vna misa cantada de rrequiem solempne, la qual acabada vayan todos juntamente con vn rresponso a la dicha nuestra capilla a lo dezir sobre nuestra sepultura. E por quanto las dichas misas non se podrán dezir todas en el dicho nuestro ospital, por la manera que dicha es, mandamos que se digan en el dicho monesterio de Sant Andrés de la dicha villa de Medina las que en el dicho ospital buenamente segund el tiempo non se podieren dezir, e los clérigos e frayres que dixieren las dichas misas en el dicho monesterio salgan a dezir los rresponsos sobre las sepulturas de nuestros padre e madre, en la nuestra capilla que tenemos en el dicho monesterio de las Honze Mill Vírgenes.

Iten mandamos, que desde el día de nuestras obsequias fasta vn anno complido, lieuen cada día ofrenda de pan, e vino, e çera al dicho nuestro ospital e otro tanto al dicho monesterio de sant Andrés, segund nuestro estado e la costumbre de la tierra lo rrequiere; e mandamos que lo lieuen dos mugeres honestas quales nombraren nuestros albaçeas, e por el trabajo de lo leuar e ofresçer, la vna al dicho ospital, la otra al dicho monesterio, e por amasar el pan les den lo que fuere rrazonable. E demás desto en fin del anno les den para su vistuario diez varas de panno a cada vna, que cueste cient maravedís la vara; pero mandamos que non les den los dineros saluo el panno para lo vestir.

Iten mandamos que, perpetuamente, los frayres del dicho monesterio de Sant Andrés digan por nuestra ánima e de nuestros padre e madre cada día (fol. $6 \mathrm{v}$ ) dos misas rrezadas en el altar de la dicha nuestra capilla de las Onze Mill Vírgenes, donde están asentados los dichos vultos de los dichos nuestro padre e madre. E por quanto nós ovimos dotado para cantar las dichas misas en la dicha nuestra capilla las nuestras heredades de Trabancos, aldea de la villa de Medina, e después el prior e frayres del dicho monesterio nos ovieron suplicado que, porque ellos non podían asý administrar las dichas heredades, que nos ploguiese de las tomar e darles otra cosa por ellas, e nós, a suplicación e pedimento les dimos e traspasamos las treynta e dos cargas de pan por medio trigo e çevada que nós teníamos de juro e heredad, por satisfaçión e emienda de las dichas nuestras heredades, para cantar las dichas misas segud ${ }^{11}$ pasó por ante escriuano público e, por ende, demás de las dichas treynta e dos cargas de pan que asý dimos al dicho monesterio en satisfaçión de las dichas heredades de Trabancos, mandamos al dicho monesterio de sant

1 Asi en el original. 
Andrés tres mill maravedís de juro e de heredad de los maravedís que nós tenemos situados, tanto que non sean de los que tenemos situados en tierra de Áuila, por quanto nós tenemos dispuesto dellos en otra manera.

Iten mandamos a nuestros albaçeas que sy en nuestra vida non sacáremos el priuilegio o priuilegios de los dichos tres mill maravedís, que ellos den e paguen lo que costare sacar el dicho priuilegio e priuilegios de los dichos tres mill maravedis a los dichos frayres, e que les den todo fauor e ayuda para sacar el dicho priuilegio o priuilegios en manera que sea sacado dentro en el anno de nuestro fallescimiento. E mandamos que los frayres que ansý dixieren las (fol. 7r) dichas misas en el dicho monesterio en la dicha nuestra capilla que salgan a dezir sus rresponsos sobre los vultos de los dichos nuestros padre e madre, los quales dichos frayres capellanes que asý dixieren las dichas misas en la dicha nuestra capilla del dicho monesterio queremos, e asý lo declaramos, que en las dichas misas cada día cada vno tenga cargo en la misa de fazer comemoraçión e suplicaçión por los dichos sennores Reyes, por los cargos que dellos tenemos. E mandamos a los visitadores que nós dexamos para el dicho nuestro ospital e de la dicha nuestra capilla, que tengan cargo de fazer, dezir e rrequerir las dichas misas, ansý en la dicha nuestra capilla del dicho nuestro ospital, commo en la dicha capilla del dicho monesterio de sant Andrés por la manera susodicha. E sy los frayres del dicho monesterio rrequeridos por los dichos visitadores non quisieren dezir las dichas misas, que los dichos nuestros visitadores puedan rremouer $e^{12}$ quitar los dichos tres mill maravedís a los dichos frayres de Sant Andrés e traspasar, e apropiar, e situarlos al dicho nuestro ospital, e los visitadores del dicho nuestro ospital pongan e acrescienten otra capellanía demás de las por nós situadas e declaradas, e paguen al capellan que la cantare segund que paguaren ${ }^{13} \mathrm{a}$ los otros capellanes que cantaren las otras capellanías en el dicho nuestro ospital, dexando al dicho monesterio de Sant Andrés las dichas treynta e dos cargas de pan, porque tengan cargo de rrogar a nuestro Sennor Dios por nuestra ánima e por aquellos de quien nós tenemos cargo por tal manera que syempre se cunpla lo que ansý ordenamos. E sy por ventura los otros dos clérigos o frayres (fol. $7 \mathrm{v}$ ) a quien los dichos nuestros visitadores eligeren para cantar e dezir las dichas capellanías en el dicho nuestro ospital, non las cantaren e dixieren, los puedan amouer e quitar segund e en la manera que se contiene en la ordenança de las Constituçiones ${ }^{14}$ que

12 Mg. en humanística: ojo.

13 Asi en el original.

14 Se refiere a unas constituciones y ordenanzas que el propio Barrientos redacta para la perfecta provisión y administración del hospital de santa María de la Piedad de Medina del Campo. 
fezimos para el dicho ospital, que fablan çerca de los dichos capellanes. Pero queremos, e ordenamos, e asý lo declaramos, que el doctor fray Fernando de Cantalapiedra, nuestro criado, por toda su vida sea vno de los capellanes del dicho nuestro ospital inmovible, e que non le puedan rremouer nin quitar los dichos nuestros visitadores; e que pueda él, por sý o por otro sostituto, seruir la dicha capellanía, e que aya a lieue el salario della como sy por sý mesmo la siruiese. Iten mandamos que en la dicha nuestra capilla del dicho monesterio de Sant Andrés se puedan ${ }^{15}$ sepultar, sy quisieren, los dichos nuestros visitadores, tanto que non fagan sepulturas altas saluo llanas, con sus lanchas de piedra labradas yguales con el suelo. E asymesmo, por esta manera, se puedan sepultar en la dicha nuestra capilla del dicho monesterio los fijos de los dichos nuestros visitadores, e nietos, e todos los otros que dellos desçendieren faziendo las dichas sepulturas segund dicho es, e non en otra manera; e aquesto se entienda a la entrada de la dicha capilla e a los lados de los vultos de los dichos nuestros padre e madre, por tal manera que non sea ninguno sepultado entre el altar e los dichos vultos ${ }^{16}$.

Otrosý, por quanto nós avemos dado e donado ${ }^{17}$ al arçipreste, clérigos e cabildo de la dicha villa de Medina çiertos bienes e heredamientos, para que perpetuamente ellos tengan cargo de dezir doze vniuersarios, los seys solepnes e los seys llanos, en el dicho nuestro ospital e en el monesterio de Sant Andrés en cada vno anno e syenpre jamás, por (fol. $8 r$ ) nuestra ánima e de nuestros defuntos, segund que más largamente se contiene en la concordia que entre nós e los dichos arçipreste e clérigos pasó. Por ende, mandamos a los dichos nuestros albaçeas e visitadores del dicho nuestro ospital, que tengan cargo de rrequerir cada vn anno a los dichos arçipreste, clérigos e cabildo que canten los dichos vniuersarios por la vía e forma que con ellos lo concordamos e pasó por escriuano, la qual dicha escriptura mandamos que esté en el ospital con las otras escripturas, en manera que todavía se cunpla nuestra voluntad commo lo concordamos con los dichos arçipreste e clérigos.

Otrosý, mandamos a los dichos nuestros albaçeas que en fin del anno después de nuestro finamiento, fagan fazer conplimiento [destas] honrras,

Es posible que este texto se completara en sucesivas redacciones, ya que, por ejemplo, en el Archivo del Ayuntamiento de Medina se encuentra una copia del siglo XVIII, en que dicho documento se fecha con posterioridad a la redacción de las disposiciones testamentarias. dores.

16 Mg. en humanistica: ojo.

17 Mg. en humanística: arcipreste, clérigos e cavildo. Doce aniversarios. 
e cabo de anno, segund e por la forma que a ellos bien visto fuere, e a nuestro estado conuiene, e en tal caso se rrequiere.

Las mandas que nós fazemos a seruiçio de nuestro Sennor Dios e descargo de nuestra conçiencia, asý a monesterios, yglesias, ospital e cofradías, como a parientes, e criados, e familiares e otras personas, son las syguientes en esta guisa.

Primeramente mandamos que el cáliçe e anpollas con que nós çelebramos en pontifical; e asymesmo las vestimentas chapadas, conuiene a saber: casulla, capa, túnica, tuniçela e alua ${ }^{18}$ con todos sus aparejos; e asymesmo el portapaz rrico en que está vn pedaço de nacar e guarnido de piedras, el qual es todo de oro; e asymesmo el nuestro pectoral rrico guarnido de piedras; e asymesmo el misal de pontifical; e asymesmo el nuestro breuiario mayor, sea todo e quede para el dicho nuestro ospital con que celebren las fiestas generales. Iten mandamos al dicho nuestro ospital la cruzeta de oro que nós tenemos en que está lignum dominicon las piedras que en ella están, para que sea puesta a esté (fol. $8 \mathrm{v}$ ) en logar deçente con las otras rreliquias del dicho ospital. Ite mandamos más al dicho ospital la casulla rrica de clemesýn ${ }^{19}$ rrico que se conpró de Ferrand Sánchez de Rueda. Ite mandamos más al dicho nuestro ospital el báculo de sant Antón que nós tenemos guarnido de plata sobredorado, para que sea puesto e esté en el logar más conueniente que se fallare en el dicho nuestro ospital. Iten mandamos más al dicho nuestro ospital las nuestras fuentes de plata sobredoradas de pontifical de bestiones ${ }^{20}$, e más los tres picheles ${ }^{21}$ de plata dorados de picos labrados que nós tenemos en logar de las anpollas, con que çelebren e honrren el altar del dicho ospital los días de las fiestas generales. Iten mandamos al dicho nuestro ospital el báculo de plata sobredorado que nós tenemos con sus cannones de plata, e las mitras menores que nós tenemos, sacando la mitra rrica la qual queremos e mandamos que sea para la yglesia mayor de Segouia.

Iten mandamos a los dichos nuestros albaçeas que den al dicho monesterio de San Andrés las vestimentas de seda morada brocada con sus aparejos. E asymesmo, mandamos al dicho monesterio de Sant Andrés, el cáliçe de plata sobredorado e vinajeras de plata con que continuamente se

\footnotetext{
18 «Diferentes vestiduras sobrepuestas que utilizan los sacerdotes en la celebración de la misa".

19 "Carmesí. Mg. en humanística: Manda el báculo de san Antón a este Hospital de la Piedad de Medina del Campo.

20 "Animal o monstruo ornamental".

21 "Jarra alta con asa y tapa sujeta a ella con un gozne".
} 
celebraua el ofiçio divino en nuestra capilla de continuo. E asymesmo, le damos el breuiario mediano en que nós rrezamos de continuo para que rrezen por él las oras a los frayres enfermos. Iten mandamos más al dicho monesterio de Sant Andrés, vn ençensario de plata que (fol. 9r) pese quatro marcos. Iten mandamos al nuestro monesterio de Sant Pedro de la Obseruancia, çerca de Riomoros, el ornamento clemesín brocado, conuiene a saber, casulla, capa, túnica, e tunicela e alua, con todo su aparejo. Iten mandamos más a estos dichos monesterios e ospital para rreparaçión de cada vno dellos veynte mil maravedís a cada vno dellos, que son sesenta mill maravedís para todos tres. Otrosý por quanto nós tenemos enprestados de los dichos monesterios de sant Andrés e de sant Pedro de Riomoros çiertos libros, los quales traemos en nuestra cámara, de los quales les dimos nuestros conosçimientos firmados del nuestro nombre de ge los tornar, por ende, mandamos a nuestros albaçeas que ge los den e tornen, e que rresçiban dellos los dichos nuestros conosçimientos. Iten mandamos más al dicho doctor fray Fernando de Cantalapiedra, nuestro criado, e al monesterio de Sant Pedro de la Obseruancia de Riomoros, porque rrueguen a nuestro Sennor Dios por nuestra ánima e por nuestros defuntos, todas las nuestras rropas de vestir. Iten mandamos más al dicho doctor, fray Fernando de Cantalapiedra, nuestro criado, todos los libros, asý de sçiencias como de rrezar, demasiados que se fallaren de que non fezimos donaçión dellos a los dichos monesterios. Iten por quanto nós ovimos dado a los dichos monesterios e ospital las sobredichas cosas, e bienes e ornamentos, por ende, sy menester es agora, asymesmo ge las damos, e por quanto después las rresçebimos dellos prestado para honrrar con ello nuestra capilla. Por ende, mandamos que avnque todas estas sobredichas cosas o parte dellas, por nós dadas a los dichos monesterios e ospital fueren falladas en nuestro poder al tiempo de nuestro fina (fol. $9 v$ ) miento, que les sean tornadas, dadas e entregadas pues que son suyas commo dicho es, e a mayor abondamiento nós desde agora les fazemos pura e perfecta donaçión dellas, que es dicha entre biuos non rreuocable en muerte nin en vida, nin en otra manera alguna por seruicio de Dios. E sy algunas dellas traemos o tenemos con nós en nuestra cámara e capilla, conosçemos e otorgamos que las tenemos dellos enprestadas e nos constituymos por poseedor dellas en su nombre del dicho nuestro ospital, e de los dichos monesterios de Sant Andrés e de Sant Pedro de Riomoros, e para ellos; e mandamos que luego les sean dadas e entregadas segund ge las ovimos dado e mandado, e dellos las rresçebimos enprestadas.

Iten mandamos al monesterio de Santa María de las Duennas, de Medina del Campo, çinco mill maravedís, e más vn cáliçe de plata dorado 
que pese tres marcos con nuestras armas, porque rrueguen a Dios por nuestra ánima e de nuestros defuntos. Iten mandamos al monesterio de Sant Bartholomé de la dicha villa de Medina, mill maravedís porque rrueguen a Dios por nuestra ánima. Ite mandamos al monesterio de Sant Sadorní de la dicha villa de Medina quinientos maravedís porque rrueguen a Dios por nuestra ánima. Iten mandamos al monesterio de Sancta Clara de la dicha villa de Medina vn cáliçe de plata en que aya dos marcos con nuestras armas, porque rrueguen a Dios por nuestra ánima. Iten mandamos a la yglesia de Sancta Maria del Antigua de la dicha villa de Medina quinientos maravedís. Iten mandamos a la yglesia de (fol. 10r) Santiago de la dicha villa de Medina vn cáliçe de plata dorado con nuestras armas en que aya tres marcos. Iten mandamos a la yglesia de sant lohán de Sardón de la dicha villa de medina vn cáliçe de plata dorado con nuestras armas en que aya tres marcos. Iten mandamos a la yglesia cathedral de nuestra sennora Sancta María de la çibdad de Segouia la nuestra mitra rrica que nós tenemos, la qual ovimos fecho e mandado fazer seyendo obispo de la dicha yglesia. Iten mandamos más a la dicha yglesia de Segouia, para conprar dos capas de seda con sus çenefas, doze mill maravedís, e mandamos que sean puestas nuestras armas en las dichas capas. Iten mandamos al monesterio de Santa Cruz de Segouia vn cáliçe de plata dorado con nuestras armas que pese tres marcos de plata. Iten mandamos al monesterio de Sancto Domingo de la dicha çibdad de Segouia, de las monjas, vn cáliçe de plata dorado con nuestras armas que pese tres marcos. Iten mandamos a la yglesia de sennor Sant Miguel de Turuégano dos mill maravedís. Iten mandados a la yglesia de Lagunillas dos mill maravedís para su rreparo. Iten mandamos a la yglesia cathedral de Sant Saluador de la çibdad de Ávila doze mill maravedís para dos capas de seda con sus çenefas. Ite mandamos a la perrochial yglesia de nuestro logar, Torralua, e a la hermita del dicho logar, a cada vna mill maravedís para rreparo dellas, que son dos mill maravedís. Iten mandamos a la yglesia de sennora Sancta Maria del nuestro logar, Serranos del Castillo, tres mill maravedís para rreparo della. Iten mandamos a la hermita del dicho logar, Serranos, (fol. 10v) que se llama Sancto Thomé, dos mill maravedis para rreparo della. Iten mandamos a la yglesia de Sant Martín de Bonilla vn cáliçe dorado con nuestras armas que pese tres marcos de plata. Iten mandamos a la yglesia de Sancta María la Mayor de Cuenca doze mill maravedís para dos capas de seda con sus çenefas rricas. Iten mandamos a la yglesia de Sancta María de Pareja un cáliçe de plata dorado con nuestras armas que pese tres marcos. Iten mandamos al monesterio de Sancto Domingo de León çinco mill maravedís por cargo que dél tenemos, e porque los frayres dél rrueguen a nuestro Sennor Dios por nuestra ánima e de nues- 
tros defuntos. Iten mandamos al monesterio de Sant Illefonso de Toro un cáliçe de plata dorado con nuestras armas en que aya tres marcos de plata por cargo que dél tenemos, e porque rrueguen a nuestro Sennor Dios los frayres del dicho monesterio por nuestra ánima e por nuestros defuntos. Iten mandamos al monesterio de Sant Pablo de Valladolid çinco mill maravedis por cargo que dél tenemos, e porque rrueguen a nuestro sennor Dios los frayres del dicho monesterio por nuestra ánima e por nuestros defuntos. Iten mandamos al monesterio de Sancto Domingo de Madrid veynte mill maravedís para rreparo del dicho monesterio, e porque las monjas dél rrueguen a nuestro Sennor por nuestra ánima e de nuestros defuntos. Iten mandamos a diez donzellas pobres de la dicha villa de Medina a cada vna diez mill maravedís para sus casamientos, sobre lo qual encargamos las conçiençias (fol. $11 r$ ) a nuestros albaçeas que las escojan las más pobres e de buena fama que fallaren, e queremos que estos maravedís non les sean dados fasta ser desposadas e al tienpo que ovieren de casar.

Iten mandamos a nuestros albaçeas que luego acabadas de fazer nuestras obsequias, con mucha diligencia fagan fazer quatro cruces a quatro puertas de la dicha villa de Medina. Conuiene a saber, la vna a la puerta que dizen de Valladolid allende de sant Sebastián donde se apartan los dos caminos, e la otra a la puerta de Santiago allende del monesterio de Sancta María de las Duennas adonde se apartan los dos caminos, e la otra a la puerta de Salamanca allende de los mesones en el mejor e más conueniente logar que vieren los dichos nuestros albaçeas, e la otra a la puerta de Ávila ençima de los barrenos; las quales dichas cruzes queremos que se fagan de piedra labrada asentadas sobre sus gradas de piedra, e tengan las dichas cruzes sus cruçifixos, e sean puestas en sendas quadreras de quinze pies en hueco, armadas sobre quatro pilares ochauados ${ }^{22}$ con su petril ${ }^{23}$ e verjas de madera labrada de fazquia ${ }^{24}$ e factión, e tabicas pintadas con nuestras armas e bien tejado con cada sendas cruzes puestas encima de los tejados, las quales dichas cruzes queremos e asý lo mandamos que cueste la obra de cada vna dellas fasta en quantía de diez mill maravedís. Otrosý mandamos que el día de nuestras obsequias den de comer a çient pobres pan, e vino, e carne o pescado segund el tienpo fuere, e acabado de comer mandamos que den a cada vno de los dichos

22 "Achaflanados".

23 "Pretil, barandilla".

24 "En la náutica un listón de tabla de cuatro o cinco dedos de ancho y del grueso de una pulgada". 
çient pobres seys varas de panno pardo. Iten mandamos que se rrepartan en el dicho día de nuestras obsequias a personas enuergonçadas e menesterosas, diez pieças de panno pardo a cada persona seys varas.

Iten (fol. $11 \mathrm{v}$ ) mandamos a todos nuestros criados, asý escuderos commo omnes de pie, e moços de espuelas: a los escuderos que non son casados a cada vno dellos diez mill maravedís para sus casamientos e a cada vno de los omnes de pie e moços de espuelas tres mill maravedís, por cargo del seruiçio que nos fizieron, e a los escuderos continuos e casados que han andado con nós e andan a cada vno quatro mill maravedís. E estos maravedís mandamos que sean dados a los dichos nuestros criados con condiçión que vayan con nuestro cuerpo e lo aconpannen fasta que sea sepultado en el dicho nuestro ospital, e estén ende fasta ser acabados los nueue dias de las obsequias, e después les sean dados e pagados los dichos maravedís a cada vno bien e conplidamente, que les non mengüe ninguna cosa dello. E mandamos a Luys de Bouadilla, sy non fuera casado quando nós pasaremos desta vida, quinze mill maravedís, e sy fuere casado, ocho mil; e a cada vno de los otros pajes, los que non touieren benefiçios, cada [uno] çinco mill maravedís. Iten mandamos a los clérigos nuestros criados que nos han seruido e non les avemos benefiçiado fasta en rrenta de diez mill maravedís a cada vno, diez mill maravedís por el cargo que dellos tenemos, e estos dichos maravedís mandamos que sean dados a los dichos nuestros criados clérigos con condiçión que vayan con nuestro cuerpo a lo aconpannar fasta que sea sepultado en el dicho nuestro ospital, e esten ende fasta ser acabados los nueue días de las dichas nuestras obsequias, segund dicho es, e después de conplidas les sean dados los dichos maravedís; pero sy los ovieremos benefiçiado en más de çinco mill maravedís o dende arriba, e nos ovieren seruido menos de çinco annos, que la satisfaçión desto (fol. 12r) quede a dispusiçión de los dichos nuestros albaçeas.

Iten mandamos a las órdenes e sanctuarios acostunbrados de la see de Salamanca, e de la Cruzada, e de la Trinidad, e de las otras órdenes a cada vna dellas veynte maravedis por seruicio de Dios e porque rrueguen a Dios por nós ${ }^{25}$.

Iten mandamos a Pedro de Barrientos, nuestro sobrino, veynte marcos de plata, e que ge los den en plateles, e taças, e jarros. Iten mandamos a Diego de Barrientos nuestro sobrino ${ }^{26}$, fijo de Iohán Sánchez de Medina,

25 Mg. en humanistica: Pedro Barrientos.

${ }_{26}$ Mg. en humanística: a Diego Barrientos 15 mil maravedis. 
quinze mill maravedís. Ite mandamos más que den al doctor fray Fernando, nuestro criado, mill doblas de oro de la vanda buenas e de justo peso, para que las él dé e distribuya en çiertas personas de quien nós tenemos cargo, las quales nós le nonbramos e declaramos.

E sy acaesçiere que nós ayamos de fallesçer e fallescamos fuera de la dicha villa de Medina, queremos, e mandamos, e damos cargo e poder al dicho fray Fernando, nuestro criado, para que luego commo nós fallescamos con toda dilegencia faga traer nuestro cuerpo a sepultar al dicho nuestro ospital, e asymesmo tome todos nuestros bienes que por entonçes en nuestro poder se fallaren en qualquier manera, por escripto o ynuentario, por ante nuestro secretario e los faga traer todos a la dicha villa de Medina, e se junte con los dichos nuestros albaçeas para conplir e executar todo lo contenido en este dicho nuestro testamento. E mandamos e encargamos a Pedro de Barrientos, nuestro sobrino, e a todos ${ }^{27}$ nuestros criados, asý clérigos commo legos, que presentes fueren al nuestro finamiento que se junten con el dicho Pedro de Barrientos para yr e aconpannar con el dicho fray Fernando nuestro cuerpo (fol. 12v) e nuestros bienes bien e fielmente, e le den todo fauor e ayuda al dicho fray Fernando para traer el dicho nuestro cuerpo, e a todos los dichos nuestros bienes, e todas las cosas que por entonçes se fallaren en nuestro poder a la dicha villa de Medina, segund dicho es. E sy el dicho Pedro de Barrientos, o alguno o algunos de los dichos nuestros criados que presentes fueren a nuestro fallesçimiento non lo quisyeren asý fazer, que por la ingratitud de aquél o aquellos que los fezieren non les sea dado nin pagado aquello que les nós mandamos, ca nós en aquel caso ge lo quitamos e rremouemos.

Iten mandamos a los dichos nuestros albaçeas que fagan dezir mill misas en el monesterio de Sancta María de Aniago, sy allí buenamente se podieren dezir, sy non, en otros monesterios o yglesias donde a ellos bien visto fuere, por el ánima del rreuerendo padre e sennor don lohan, de buena memoria, obispo que fue del obispado de Segouia, nuestro anteçesor, por descargo de nuestra conçiençia sy dél algund cargo tenemos.

Iten por quanto ha grandes días que nós tenemos los esclauos e esclauas que agora son en nuestra casa, e nos han seruido bien, por tanto por seruiçio de nuestro sennor Dios los fazemos libres e esentos a todos los dichos nuestros esclauos e esclauas que tenemos christianos, para que de aquí adelante puedan fazer de sý lo que querrán, que ninguna nin algunas personas non los puedan tomar nin tomen por esclauos, por

27 Mg. en humanística: Pedro. 
quanto es nuestra intençión que sean forros ${ }^{28} \mathrm{e}$ libres de aquí adelante commo dicho es. E los que fueren moras ${ }^{29}$ e moras que sean trocados e trocadas, e vendidos e vendidas para rrescatar e rredemir algunos christianos captiuos.

Iten por quanto nós ovimos dado al (fol. 13r) dicho monesterio de Sant Andrés çiertos solepnes libros e joyas, e de grand valor, los quales ovimos puesto en la libreria del dicho monesterio de Sant Andrés; por ende, queremos, e mandamos, e asý lo declaramos, e es nuestra voluntad que los dichos libros e joyas que asý ovimos donado e dado al dicho monesterio, que estén perpetuamente los dichos libros en la librería del dicho monesterio, e las joyas en el logar donde se rreconden e guardan las semejantes cosas, e que ningud ${ }^{30}$ prouinçial, nin el prior e frayres del dicho monesterio que agora son o serán de aquí adelante, nin otro ninguro por ellos 10 puedan vender, nin dar, nin prestar, nin enajenar, nin cambir, nin trocar por ninguna manera que sea. E sy acaesçiere que lo contrario fizieren o alguno dellos fiziere por eso mismo fecho, mandamos que los visitadores del dicho nuestro ospital puedan tomar los dichos libros e joyas, e pasarlo, e ponerlo en logar conueniente en el dicho nuestro ospital; e mandamos que el inuentario de todas las dichas cosas e libros esté en el dicho nuestro ospital con las otras escripturas. Iten mandamos que esto mesmo se entienda en las cosas que dimos al dicho nuestro monesterio de Sant Pedro de la Obseruançia, çerca de Riomoros, e para esto queremos e mandamos que los dichos visitadores vean las dichas cosas en los tienpos que ellos quisyeren e a ellos bien visto fuere, e que puedan conpeller a los priores e frayres de los dichos monesterios de sant Andrés e de sant Pedro que ge lo muestren, porque syenpre esté de (fol. 13v) manifiesto e non perezcan las dichas cosas.

Iten por quanto el dicho fray Fernando de Cantalapiedra, nuestro criado, ovo rresçebido e rrecabdado por nós çiertas quantías de maravedís, e oro, e plata, e joyas, e otras cosas fasta oy de la data deste nuestro testamento, de lo qual todo él nos dio buen rrecabdo e cuenta e rrazón, de que nós somos contento e pagado de todo ello sobre lo qual nós le ovimos dado nuestro fin e quito firmado de nuestro nonbre por saneamiento suyo para que él sea libre e contra él non se aya recurso alguno. Por ende, a mayor abondamiento por la presente, damos por libre e quito al dicho fray Fernando de todo lo que asý en nuestro nonbre ha rresçebido e rrecab-

28 "Horros, manumisos".

29 Asi en el original.

30 Así en el original. 
dado fasta oy dicho día, segund e por la vía que se contiene en el dicho fin e quito que sobre esto le avemos dado.

Iten mandamos e queremos e asý lo declaramos que todas las cosas e bienes nuestros rrestantes afuera de lo por nos mandado en este nuestro testamento que fazemos, e por otras escripturas abténticas firmadas de nuestro nonbre e signadas de nuestro secretario, ansý oro como plata, e dinero, e joyas, e debdas, e bienes muebles e rraýzes, que lo aya e herede todo el dicho nuestro ospital ${ }^{31}$, al qual dexamos e instituymos por nuestro heredero vniuersal en todos los dichos nuestros bienes rremanesçientes.

Iten mandamos que todas e qualesquier persona o personas, o villas 0 logares que dixieren que les somos tenudo en alguna cosa, que en tal caso nuestros albaçeas ayan dello verdadera informaçión e les paguen e satisfagan de aquella que verdaderamente se fallare que nós les somos obligado e en cargo. Iten mandamos (fol. 14r) que den a los dichos nuestros testamentarios e albaçeas por su trabajo ocho mill maravedís a cada vno. Iten mandamos que por quanto Vraca ${ }^{32}$ Gónçales de Contreras nos ovo encargado que fiziesemos fazer vnos vultos en la çibdad de Ávila, los quales nós tenemos pagado a Pero Gonçálves de Fuentiueros, canónigo en la yglesia de Ávila, e él es tenudo e obligado a los pagar a maestro haniquiz, vezino de Tolledo; por ende, encargamos a los dichos nuestros albaçeas que conpellan al dicho Pero Gonçáles de Fuentiueros que pague al dicho maestro Haniquiz que los acabe e asyente en la dicha çibdad de Ávila, en el logar e por la manera que se obliga en el contracto que sobre ello fizo, el qual contracto está en poder del dicho Pero Gonçáles de Fuentiueros lo qual mucho encargamos a los dichos nuestros albaçeas que fagan asý por descargo de nuestra conçiencia. E demás desto, mandamos que digan mill misas por el ánima de la dicha Vrraca Gonçáles de Contreras, asý en la yglesia a do ella está sepultada, como en las yglesias de la dicha çibdad de Ávila.

E para conplir e pagar todas las mandas e cosas en este nuestro testamento contenidas, <e> estableçemos ${ }^{33}$, e constituymos, e nonbramos por nuestros albaçeas e executores de este dicho nuestro testamento e testamentarios, al honrrado e discreto varón don Nunno Gonçáles del Alguila, arçediano de la yglesia mayor de la çibdad de Ávila, e al dicho doctor fray Fernando nuestro criado, e a Diego de Barrientos, nuestro (fol.

Mg. en humanística: Heredero el hospital de la Piedad de Medina.

Así en el original.

Mg. en humanística: albaceas. 
14v) sobrino ${ }^{34}$ fijo de lohán Sánchez de Medina, rregidor de la dicha villa de Medina, a los quales todos tres juntamente o a la mayor parte dellos, damos liçencia e auctoridad, e mandamos que entren e tomen e se apoderen de todos nuestros bienes muebles e rraýzes asý oro commo plata, e dineros, e joyas, e libros, e rropas de estrado, e paramentos, e mantas, e pannos de pared, e rropa de camas e de estrado, e pan, e vino, e ganados, e cauallos, e mulas, e azémilas, e otras qualesquier cosas e bienes que nós tengamos en qualquier parte e logar, asý de los fructos e rrentas del dicho nuestro obispado commo de otros qualesquier nuestros bienes; ca nos por la presente les damos e otorgamos todo nuestro poder conplido para ello, e asymesmo para que puedan sacar e saquen libramiento e libramientos de los libros del Rey nuestro sennor de los maravedís que de su Alteza tenemos e nos fueren deuidos, asý de juro de heredad como de merçed, de por vida cornmo de mantenimiento, rraçión e quitaçión e de otra qualquier manera, e reçebirlos e rrecabdarios de qualesquier rrecabdador e recabdadores e rreçeptores del dicho sennor Rey, e para que puedan demandar, e resçebir, e aver, e cobrar todas las sobredichas cosas, e cada vna dellas de qualesquier persona o personas que las touieren e nos las deuieren e ovieren de dar, e todas otras qualesquier debdas que en qualquier manera nos devan e nos pertenesçieren en qualquier manera $e$ por (fol. 15r) qualquier rrazón, e para çerca de todo ello e de cada vna cosa e parte dello, puedan fazer e fagan todas las cosas que nós mesmo faríamos presente seyendo asý en juyzio commo fuera dél.

E por la presente annullamos e rreuocamos e damos por ninguno todo otro qualquier testamento o testamentos, e codecillo o codecillos que nós ayamos fecho e otorgado ante deste nuestro testamento fasta agora en qualquier manera, por quanto este presente nuestro testamento que agora fazemos damos e otorgamos por nuestro verdadero testamento e por viltima nuestra voluntad, la qual mandamos que vala commo testamento nuestro, e sy non valiere commo nuestro testamento, que vala commo nuestro codeçillo, e sy non valliere por codeçillo, que vala pro expresa e v́ltima nuestra voluntad en que nos afirmamos. E puesto que parescan dos o tres o quatro o más testamentos fechos e otorgados ante vn notario e en vn dia, mes e anno, e todos en vn thenor queremos e asý lo declaramos e mandamos, que sea entendido que todos ellos sean avidos por vno solo nuestro testamento e non más, por quanto nós a sabiendas por algunas justas causas e rrazones que a ello nos mouieron e mueuen, otorgamos e 
fazemos e construymos en vn thenor desto que dicho es quatro testamentos, de los quales mandamos que el vno dellos esté en el sagrario del dicho nuestro ospital con las escripturas dél, e el otro en el dicho monesterio de sant Andrés, e el otro en el dicho monesterio de Sant Pedro de la Obser (fol. 15v) vancia cabo Riomoros, e el otro que esté con nós en nuestra cámara; e porque esto sea firme e non venga en dubda, otorgamos esta carta e instrumento deste nuestro testamento en la manera que dicha es ante Velasco Sánchez, canónigo en la yglesia de Segouia, notario público apostolical, al qual rrogamos lo escriuiese o fiziese escreuir, e que fiziesen dello las dichas quatro copias e instrumentos de este nuestro testamento en vn thenor, e las sygnase de su sygno. E a los que presentes estauan rrogamos que fuessen dello testigo, de lo qual son testigo que para esto que dicho es por nós espeçialmente fueron llamados e rrogados: Álvaro de Bracamonte, e Juan Gutiérrez, e el liçençiado Ferrand Ruyz, e Francisco Ruyz, su hermano, e Johan Rodríguez fijo de Ferrand Rodríguez, e Alfonso Álvarez, su hermano, vezinos de la dicha villa de Medina, e Ferrand López de Bonilla, escriuano de cámara del rrey nuestro sennor, vezino de la dicha villa de Medina.

Fecha e otorgada fue esta carta e instrumento de testamento en quatro cartas e instrumentos de testamentos por el dicho sennor don Lope de Barrientos, obispo de Cuenca, chançiller mayor del Rey nuestro sennor, e su confessor e oydor de la su audençia e del su consejo, en la dicha villa de medina, a ${ }^{35}$ diez e syete días del mes de nouienbre, anno del nasçimiento del nuestro saluador Ihesuchristo de mill e quatrocientos e cinquenta e quatro annos. Inutilus Christi servus.

[Rúbricas] L. episcopus Conchensis, Álvaro de Bracamonte, Johannis Gutiérrez, Ferrandus Licenciatus, Juan Rodríguez, Franciscus Ruiz, Alonso Álvares, Ferrand López.

(Signo) Apostolicus notarius. E yo, el dicho Velasco Sánchez, escrivano en la eglesia de Segouia, notario público por la abtoridad apostolical, fuy presente a todo lo que dicho es, e a cada vna cosa, e parte dello en vno con los dichos testigos, e por ende a rruego, pedimiento e requerimiento del dicho sennor obispo don Lope de Barrientos, obispo de Cuenca, chançiller mayor del Rey nuestro sennor, e su confesor e oydor de la su abdiençia e del su consejo, este instrumiento de testamento por otro fielmente fiz escriuir yo, ocupado de otros muchos e arduos negoços, e fiz este mi sygno e nonbre acostunbrados en testamiento de verdad, el

Mg. en humanística: Fecha 17 de noviembre de 1454. 
qual va escripto en diez e seys fojas con ésta en que va este mi sygno, e firmado otrosý del dicho sennor obispo e de cada vno de los dichos testigos, e en cada plana mi rúbrica e nonbre acostunbrados, rrogado e rrequerido. 